\title{
Ontario newborns now screened for SCID
}

$\mathrm{O}$ ntario is the first Canadian province to screen babies for a rare genetic condition in which they are born without a functioning immune system, leading to severe infections and often death before their first birthday.

Severe combined immune deficiency (SCID) is fatal unless the child receives a working immune system, usually through a bone marrow transplant. Screening at birth with a blood test allows doctors to identify the disease before a baby gets infections, allowing for early treatment. Approximately 1 in 100000 babies is born with SCID.

Newborn Screening Ontario and Ontario Health Minister Deb Matthews announced the program at the Children's Hospital of Eastern Ontario (CHEO) in Ottawa, Ontario, on Aug. 20.

At the announcement, Lori Peters told the story of losing her second daughter, Brooklyn, to SCID. Brooklyn seemed healthy when she was born in 2001, said Peters. But over the next weeks and months, she became increasingly ill. Her parents took her to the hospital repeatedly, but doctors did not know what was wrong with her until a blood sample taken hours before she died revealed the cause. By then it was too late.

"The most frustrating part of losing our beautiful daughter was that she was never given a chance to fight," Peters said. "We never knew what we were fighting."

The family had a healthy daughter a year and a half later, who was screened for SCID. Two years after that, they had a newborn baby boy, Ethan.

Ethan had SCID, but because he was screened early, he received treatment. He was put in isolation for 253 days and then received a bone marrow transplant. Ethan is now eight years old and wants to play hockey for the Toronto Maple Leafs when he grows up.

"Ethan is here as a living example of what can happen for babies who are screened early," said Matthews. Screen-

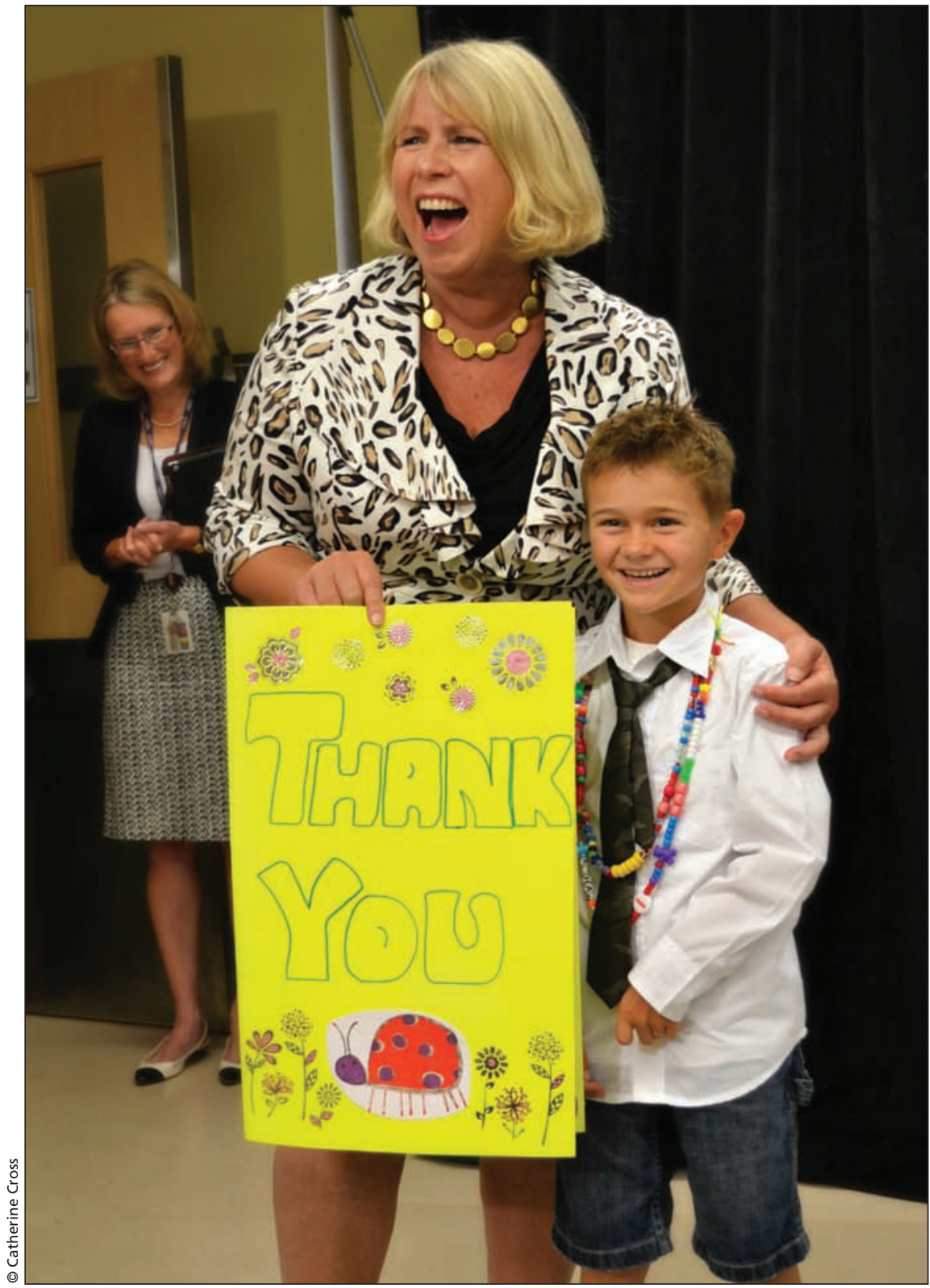

SCID survivor Ethan Peters presents a card to Ontario Health Minister Deb Matthews. Ethan wears his "bravery beads" from Toronto's Hospital for Sick Children around his neck. He has more than 150 beads.

ing every Ontario newborn for the disease will help identify $5-10$ babies with SCID per year.

"Their families will be saved from the anguish and pain that our family endured," says Peters.

Newborn Screening Ontario is a provincial program that has tested more than one million newborns for 29 rare, treatable diseases. Since the program moved to CHEO in 2006, more than 1250 babies have been identified with diseases through newborn screening. Catherine Cross, CMAJ

CMAJ 2013. DOI:10.1503/cmaj.109-4580 